\title{
DIGITALCOMMONS
}

$@$ WAYNESTATE-

\section{Human Biology}

Volume 85

Issue 1 Special Issue on Revisiting the "Negrito"

Article 11

Hypothesis

2013

\section{Mount Pinatubo, Inflammatory Cytokines, and the Immunological Ecology of Aeta Hunter-Gatherers}

Robin M. Bernstein

Department of Anthropology, George Washington University, Washington, DC, robin.bernstein@colorado.edu

Nathaniel J. Dominy

Department of Anthropology, Dartmouth College, Hanover, NH, nathaniel.j.dominy@dartmouth.edu

Follow this and additional works at: http://digitalcommons.wayne.edu/humbiol

Part of the Biological and Physical Anthropology Commons, and the Genetics and Genomics Commons

\section{Recommended Citation}

Bernstein, Robin M. and Dominy, Nathaniel J. (2013) "Mount Pinatubo, Inflammatory Cytokines, and the Immunological Ecology of Aeta Hunter-Gatherers," Human Biology: Vol. 85: Iss. 1, Article 11.

Available at: http://digitalcommons.wayne.edu/humbiol/vol85/iss1/11 


\title{
Mount Pinatubo, Inflammatory Cytokines, and the Immunological Ecology of Aeta Hunter-Gatherers
}

\begin{abstract}
Early growth cessation and reproduction are predicted to maximize fitness under conditions of high adult mortality, factors that could explain the pygmy phenotype of many rainforest hunter-gatherers. This lifehistory hypothesis is elegant but contentious in part because it lacks a clear biological mechanism. One mechanism stems from the field of human immunological ecology and the concept of inflammation "memory" across the life cycle and into subsequent generations. Maternal exposures to disease can infl uence immunological cues present in breast milk; because maternal provisioning via lactation occurs during critical periods of development, it is plausible that these cues can also mediate early growth cessation and small body size. Such epigenetic hypotheses are difficult to test, but the concept of developmental programming is attractive because it could explain how the stature of a population can change over time, in terms of both secular increases and rapid intergenerational decreases. Here we explore this concept by focusing on the Aeta, a population of former hunter-gatherers, and the Ilocano, a population of rice farmers. We predicted that Aeta mothers would produce breast milk with higher concentrations of four bioactive factors due to high infectious burdens. Further, we predicted that the concentrations of these factors would be highest in the cohort of women born in the early 1990s, when exposure to infectious disease was acute following the eruption of Mount Pinatubo in June 1991. We analyzed levels of adiponectin, C-reactive protein, and epidermal growth factor in the milk of 24 Aeta and 31 Ilocano women and found no detectable differences, whereas levels of transforming growth factor- $\beta_{2}$ were elevated among the Aeta, particularly as a function of maternal age. We found no difference between cohorts divided by the volcanic eruption ( $n=43$ born before, $n=12$ born after). We discuss the implications of our findings for the terminal investment hypothesis and we suggest that the historical ecology of the Aeta is a promising model system for testing epigenetic hypotheses focused on the evolution of small body size.
\end{abstract}

\section{Keywords}

Aeta, Adiponectin, C-Reactive Protein, Epidermal Growth Factor, Negrito, Phenotypic Plasticity, Philippines, Transforming Growth Factor Beta. 


\title{
Mount Pinatubo, Inflammatory Cytokines, and the Immunological Ecology of Aeta Hunter-Gatherers
}

ROBIN M. BERNSTEIN ${ }^{1} *$ AND NATHANIEL J. DOMINY ${ }^{2,3} *$

\begin{abstract}
Early growth cessation and reproduction are predicted to maximize fitness under conditions of high adult mortality, factors that could explain the pygmy phenotype of many rainforest hunter-gatherers. This life-history hypothesis is elegant but contentious in part because it lacks a clear biological mechanism. One mechanism stems from the field of human immunological ecology and the concept of inflammation "memory" across the life cycle and into subsequent generations. Maternal exposures to disease can influence immunological cues present in breast milk; because maternal provisioning via lactation occurs during critical periods of development, it is plausible that these cues can also mediate early growth cessation and small body size. Such epigenetic hypotheses are difficult to test, but the concept of developmental programming is attractive because it could explain how the stature of a population can change over time, in terms of both secular increases and rapid intergenerational decreases. Here we explore this concept by focusing on the Aeta, a population of former hunter-gatherers, and the Ilocano, a population of rice farmers. We predicted that Aeta mothers would produce breast milk with higher concentrations of four bioactive factors due to high infectious burdens. Further, we predicted that the concentrations of these factors would be highest in the cohort of women born in the early 1990s, when exposure to infectious disease was acute following the eruption of Mount Pinatubo in June 1991. We analyzed levels of adiponectin, C-reactive protein, and epidermal growth factor in the milk of 24 Aeta and 31 Ilocano women and found no detectable differences, whereas levels of transforming growth factor- $\beta_{2}$ were elevated among the Aeta, particularly as a function of maternal age. We found no difference between cohorts divided by the volcanic eruption $(n=43$ born
\end{abstract}

\footnotetext{
${ }^{1}$ Department of Anthropology, George Washington University, Washington, DC.

${ }^{2}$ Department of Anthropology, Dartmouth College, Hanover, NH.

${ }^{3}$ Department of Biological Sciences, Dartmouth College, Hanover, NH.

*Correspondence to: Robin M. Bernstein, Department of Anthropology, University of Colorado, Boulder, CO 80309. E-mail: robin.bernstein@colorado.edu. Nathaniel J. Dominy, Department of Anthropology, Dartmouth College, Hanover, NH 03755.E-mail: nathaniel.j.dominy@dartmouth.edu.
}

Human Biology, February-June 2013, v. 85, no. 1-3, pp. 231-250.

Copyright (C) 2013 Wayne State University Press, Detroit, Michigan 48201-1309

KEY WORDS: AETA, ADIPONECTIN, C-REACTIVE PROTEIN, EPIDERMAL GROWTH FACTOR, NEGRITO, PHENOTYPIC PLASTICITY, PHILIPPINES, TRANSFORMING GROWTH FACTOR BETA. 
before, $n=12$ born after). We discuss the implications of our findings for the terminal investment hypothesis and we suggest that the historical ecology of the Aeta is a promising model system for testing epigenetic hypotheses focused on the evolution of small body size.

Tropical rainforests can be challenging environments for hunter-gatherers; parasitic and infectious disease species abound at low latitudes (Guernier et al. 2004), and the risk of predation is high for some populations (Headland and Greene 2011). As a result, tropical hunter-gatherers often endure relatively high rates of agespecific mortality (Hill et al. 2007). For instance, the mortality rates of African hunter-gatherer infants and children younger than 5 years are $20 \%$ and $27-40 \%$, respectively, or twice the regional rate (Ohenjo et al. 2006). In the Philippines, the mortality rate of Agta children younger than 5 years can reach $45 \%$ (Early and Headland 1998). These high rates also extend into adulthood: among six rainforest hunter-gatherer populations from Africa and Southeast Asia, the chances of surviving to age 15 are $30-51 \%$, versus $59-76 \%$ for one pastoralist and two non-rainforest hunter-gatherer populations (Migliano et al. 2007). At 15 years of age, the ensuing life expectancy estimates for these two groups are 20-32.5 and 41.5-46.6 years, respectively (Migliano et al. 2007).

Under circumstances of high mortality, an early cessation of growth or a diminished growth spurt that facilitates early reproduction is expected to maximize fitness. Thus, for rainforest hunter-gatherers, early maturation could be the primary (although not exclusive) cause of the human pygmy phenotype (Walker et al. 2006; Migliano et al. 2007, 2010). Indeed, the growth curves of rainforest huntergatherer females level off at around age 12, at a time when for other populations the adolescent growth spurt is just beginning (Walker et al. 2006; Migliano et al. 2007). In an extension of this model, Walker and Hamilton (2008) considered the effects of population densities on human body-size variation, as population density might be positively correlated with both resource constraint and mortality in similar environments (e.g., across tropical rainforests).

These life-history hypotheses for the pygmy phenotype are elegant but also contentious due to emerging evidence for genetic determination (Perry and Dominy 2009; Becker et al. 2010, 2011; Jarvis et al. 2012; Lachance et al. 2012; Migliano et al. this issue). Furthermore, the biological mechanisms underlying the life-history hypotheses are uncertain: how do high rates of mortality or, rather, the prevalent causes of mortality, such as disease and nutritional stress, induce earlier reproductive maturity in some but not all (see Hill and Hurtado 1996) populations of hunter-gatherers? A plausible but underexplored mechanism stems from the emerging field of human immunological ecology (McDade 2003, 2005) and the concept of inflammation "memory" across the life cycle and in subsequent generations (McDade et al. 2011; Thayer and Kuzawa 2011; Kuzawa et al. 2012; Thayer et al. 2012; Tallman et al. 2012). Here we explore and attempt to test this epigenetic premise. 
Maternal Environment and Developmental Programming. Given that fetal life and infancy are critical periods for developmental programming, and that these periods overlap with maternal provisioning via gestation and lactation, it is plausible that maternal exposures to disease or nutritional stress can influence immunological cues that are transmitted in the placenta and breast milk (Moore et al. 2006; Kuzawa and Quinn 2009; Kuzawa and Thayer 2011). Cues such as the level of inflammatory cytokines during gestation could mediate lower birth weights (Kuzawa 2005) and drive the correlation between lower birth weights and earlier menarche (Adair 2001) and, in turn, the correlation between early menarche and small body size (Walker et al. 2006; Migliano et al. 2007). Although epigenetic hypotheses are difficult to test (Ellison and Jasienska 2007), the concept of fetal programming, or induction, is an attractive unifying mechanism for body size changes at all temporal scales, ranging from rapid intergenerational decreases associated with infectious diseases (Stock and Migliano 2009) to secular increases associated with improved nutrition (Katzmarzyk and Leonard 1998; Kirchengast 2000). It also unites different hypotheses focused on the Agta: maternal cues associated with disease (Migliano et al. 2007), nutritional stress (De Souza 2006), or both, could explain how early reproductive maturity is being mediated.

Most research on developmental programming has emphasized modifications in utero and the effects of early-life nutrition. Yet maternal influences on development extend beyond birth; breast milk is the primary food source for all mammalian newborns and a medium of chemical messages (Bernt and Walker 1999). For example, milk delivers an array of bioactive molecules that not only confer immunoprotection but also shape the microbiome and physiology of the developing gastrointestinal tract (Rautava and Walker 2009; D'Alessandro et al. 2010). Breast milk can also contain high concentrations of nonspecific defense factors that reflect a lifetime of maternal antigenic experiences, and the immunologic protection being conferred to an infant is often specific to local disease conditions (McDade and Worthman 1999). Breast-feeding is thus the functional integration of maternal and offspring immune systems (Brandtzaeg 2010). Yet milk is not merely a conduit of immune factors from mother to offspring; it also contains proteins that direct the development of the infant immune system (Petherick 2010), along with several other factors that probably shape neonatal growth and metabolism (Savino et al. 2010b).

Thus, breast milk can transmit information about maternal developmental history (especially with regard to immune development) and current physiological state (e.g., body composition, state of infection), as discussed below. These bioactive factors have the potential to function as cues or "programming" agents and to provide a mechanism for communicating an optimal growth strategy to the developing fetus or infant. This communication can endure for several years, and it has the potential to improve reproductive fitness.

Here we explore this concept by reporting immunological cues in the breast milk of Ilocano and Aeta women. The Ilocano are sedentary rice farmers, whereas the Aeta are former hunter-gatherers with an average adult male height of $\sim 150$ $\mathrm{cm}$ (Table 1). This adult stature, or pygmy phenotype, is strongly associated with 
Table 1. Mean Adult Statures of Aeta Populations in Western Luzon

\begin{tabular}{lllll}
$\begin{array}{l}\text { YEAR(s) OF DATA } \\
\text { COLLECTION }\end{array}$ & PROVINCE & \multicolumn{2}{l}{ AVERAGE ADULT HEIGHT [CM $(n)]$} & REFERENCE \\
\hline 1903 & & MALE & FEMALE & \\
$1901-1909$ & Zambales & $146.3(48)$ & $137.8(29)$ & Reed 1904 \\
1912 & Bataan & $145.4(9)$ & $135.5(10)$ & Barrows 1910 \\
$1938-1939$ & Bultiple & $147.0(147)$ & $138.0(50)$ & Newton 1920 \\
$1975-1977$ & Pampanga & $147.5(97)$ & $137.8(59)$ & Schebesta 1952 \\
$1975-1982$ & Bataan; Zambales & $150.1(81)$ & $140.5(58)$ & Omoto 1989 \\
2001 & Pampanga & $149.4(23)$ & $137.2(73)$ & Allingham 2008 \\
$2002-2003$ & Zambales & $150.0(146)$ & $140.0(209)$ & Migliano 2005; \\
& & & & Migliano et al. 2007 \\
\hline
\end{tabular}

${ }^{a}$ Data are based on middle-age adults and converted from inches; Allingham (2008) also reported mean heights for younger adults (men: $152.1 \mathrm{~cm}, n=7$; women: $137.2 \mathrm{~cm}, n=18$ ) and older adults (men: $140.0 \mathrm{~cm}, n=41$; women: $135.1 \mathrm{~cm}, n=63$ ).

rainforest habitats (Perry and Dominy 2009; Figure 1A). For many Aeta, this habitat was destroyed by the paroxysmal eruption of Mount Pinatubo on 15 June 1991 (Figure 1B). The eruption was cataclysmic, producing pyroclastic flows and depositing $>5 \mathrm{~km}^{3}$ of pumiceous debris on the volcano flanks (Figure 1C). In ensuing years, torrential, typhoon-enhanced monsoonal rains mobilized great volumes of debris into destructive lahars that flowed down all major drainages of the volcano (Figure 2), damaging or obliterating many villages and towns (Newhall et al. 1996). As a result, the majority of Aeta evacuated the mountain and experienced a sudden and profound change in environmental circumstances, possibly for the second time in $\sim 500$ years (Rodolfo and Umbal 2008).

Aeta before and after 1991. The Aeta share a common ancestor with the Agta (HUGO Pan-Asian SNP Consortium 2009; Delfin et al. 2011), a hunter-gatherer population in northeastern Luzon (Peterson 1978; Griffin and Estioko-Griffin 1985; Rai 1990). The Aeta and Agta have similar life-history attributes-high mortality, early maturation, short stature (Migliano et al. 2007) - and early accounts indicate comparable foraging ecologies (Reed 1904; del Fierro, 1918; Newton 1920; Schebesta 1952; Garvan and Hochegger 1964). Accordingly, the eruption of Mount Pinatubo is often perceived as a rare opportunity to examine how a hunter-gatherer culture responds to an abrupt shift in subsistence ecology (Shimizu 1992; Seitz 1998, 2004, 2008; Gaillard 2006, 2007; Gaillard and Le Masson 2007; Acaba 2008; Rusznak 2010; Marler 2011). However, many Aeta practiced swidden agriculture before the eruption (Fox 1952; Shimizu 1989), perhaps for several centuries (Brosius 1990). The adversity associated with resettlement and sedentary agriculture has therefore varied widely (Gaillard 2006, 2007; Gaillard and Le Masson 2007). 


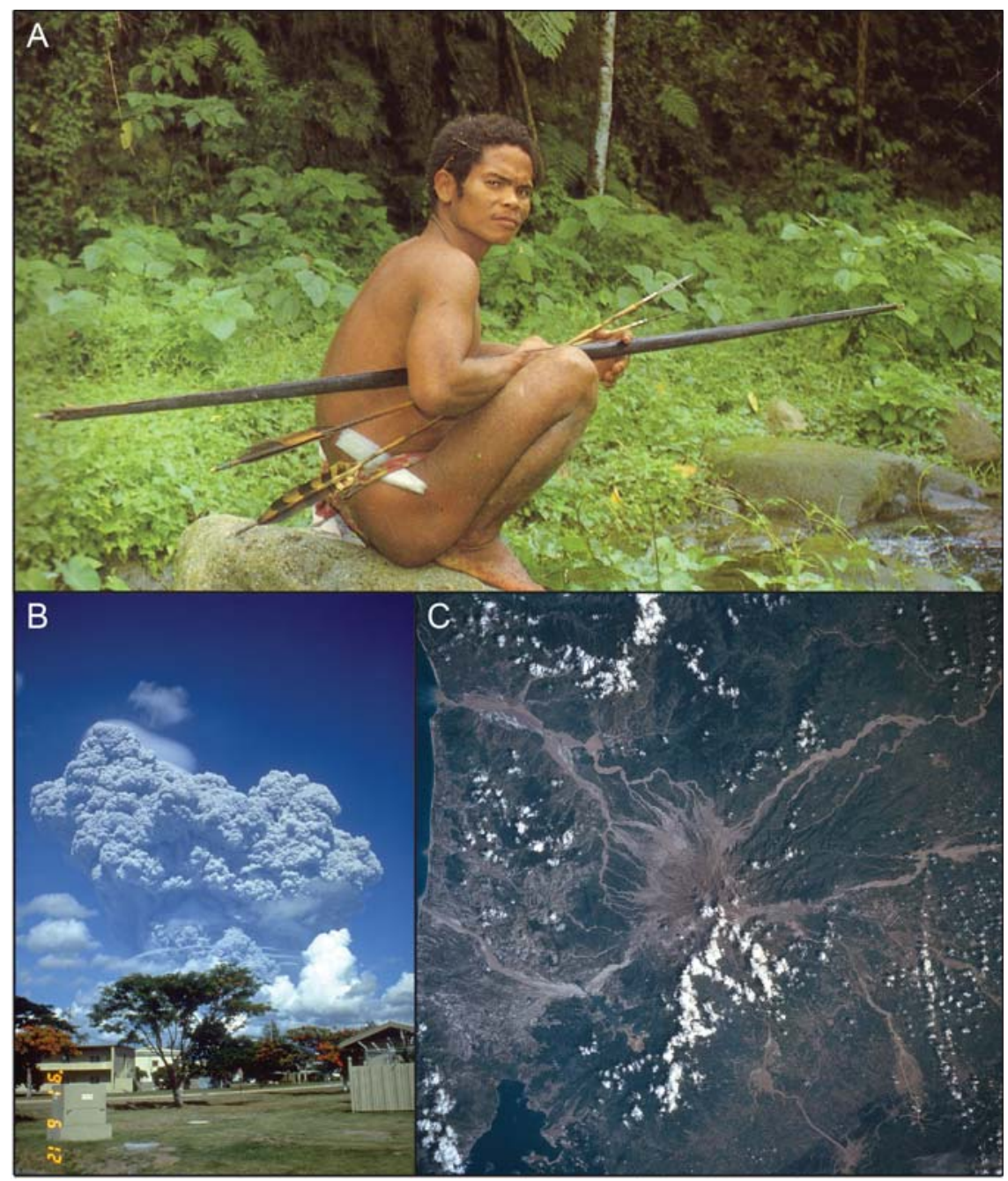

Figure 1. (A) Aeta hunter on the slopes of Mount Pinatubo circa 1980s [photograph by Carmen G. Balazo, reproduced with permission from Negrito Peoples Alliance of Zambales (LAKAS)]. (B) Eruption column of Mount Pinatubo on 12 June 1991, three days before the climactic eruption (photograph by Richard P. Hobblitt, reproduced with permission from the U.S. Geological Survey Cascades Volcano Observatory). (C) Mount Pinatubo several days following the eruption and after heavy monsoon rains triggered lahars down all major drainages. The wide expanse of still-cooling pyroclastic flow is apparent on the western slope (image STS046-75-79A, courtesy of the Science and Analysis Laboratory, NASA Johnson Space Center). 
In the early 1900 s, the mortality rate of Aeta children was $\sim 45 \%$ (Newton 1920). A secular increase in stature during the past century (Table 1) could indicate decreasing rates of morbidity and mortality, although data are scant. Reports of relatively high morbidity rates in another negrito population, the Ati, suggest that the Aeta faced comparable conditions during the 1980s (Cadeliña and Cadeliña 1988). This supposition is consistent with serological data from the 1990s that indicate widespread undernourishment among the Aeta (Dávila et al. 2002). Taken together, these lines of evidence suggest that the Aeta living on or near Mount Pinatubo endured relatively high rates of morbidity and mortality before 1991. In the immediate aftermath of the eruption, these rates increased disproportionately in the crowded evacuation centers.

Sawada (1992) reported 114,217 total evacuees, of which 22,723 (19.9\%) were Aeta, and yet the Aeta accounted for 447 (92.5\%) of 483 deaths between 16 June and 11 October 1991. The primary causes of death were attributed to measles (35\%), pneumonia (34\%), and malnutrition (11\%). Overall, morbidity and mortality were greatest among infants and children 0-4 years of age (Sawada 1992). The subsequent resettlement of the Aeta into government-sponsored communities improved matters, but destructive lahars and floods continued to visit devastation on the region (Bautista 1996; Umbal 1997). Current population densities in these communities ( 0.9 people/ $\mathrm{km}^{2}$; Migliano 2005) are greater than before the eruption (Seitz 2004), and Aeta mortality rates remain distressingly high (Migliano et al. 2007).

This immunological history is predicted to result in breast milk with high concentrations of certain bioactive factors associated with disease and nutritional stress, and their subsequent chronic influence on maternal physiology. Such milk could signal a different growth trajectory to developing infants compared with that of Ilocano mothers, whose immunological histories are likely to be different; further, we predict such cues to manifest most strongly in the cohort of women born in the early 1990s, when Aeta maternal and infant exposures to infectious disease and nutritional stress were acute. To test these hypotheses, we report concentrations of adiponectin, $\mathrm{C}$-reactive protein (CRP), epidermal growth factor (EGF), and transforming growth factor- $\beta_{2}$ (TGF- $\left.\beta_{2}\right)$ in the breast milk of Aeta and Ilocano mothers born before and after the eruption of Mount Pinatubo. By testing these predictions, we examine whether these milk-borne compounds might function as conduits for phenotypic information transfer between generations and link maternal experiences with offspring biology.

Adiponectin. Adiponectin is an adipocyte-secreted cytokine, or adipokine, involved in metabolic processes such as increasing insulin sensitivity and mediating inflammation (Newburg et al. 2010). In particular, adiponectin reduces the production of proinflammatory cytokines while having potent anti-inflammatory effects across a wide range of tissues (Wulster-Radcliffe et al. 2004; Zhou et al. 2005). Milk adiponectin derives from the transfer of maternal circulating adiponectin and/or synthesis in mammary tissue (Weyermann et al. 2006). In general, lower infant weights and leaner body compositions are associated with higher 
levels of adiponectin, at least through the first six months of life (Newburg et al. 2010; but see Woo et al. 2012). The fact that of adiponectin levels in breast milk can fluctuate with maternal energy balance and also in response to preterm or underweight infants suggests that it plays a key role in mediating the adaptive responses of infant adipose tissues (Savino et al. 2008, 2010a; Woo et al. 2009). Adiponectin levels also correlate with linear growth, perhaps because adiponectin activates osteoblasts (Oshima et al. 2005).

C-Reactive Protein. CRP is an acute-phase inflammatory protein, typically elevated during infections (Danesh et al. 2004). Circulating levels of CRP have been measured in a number of populations with different subsistence strategies and levels of pathogen exposure (e.g., Imrie et al. 2007; Nettleton et al. 2008). For example, the Tsimane of Bolivia face chronic infections throughout life and have higher levels of CRP than age-matched cohorts in the United States, a difference that has been implicated as a contributing factor to their small stature (Gurven et al. 2008). Similarly, a positive correlation between infectious symptoms and CRP concentrations also exists in Philippine populations (McDade et al. 2008, 2010); however, median values are lower than those in the United States (McDade et al. 2009), a pattern that argues against an inverse relationship between CRP levels and adult stature. Maternal infections might influence CRP levels in breast milk, but data are sparse. Fetherston et al. (2006) reported higher concentrations of CRP in the milk of mothers with mastitis versus those without mastitis and with infective (i.e., bacterial) versus noninfective mastitis. Results also indicated transfer of systemic CRP into breast milk, since milk from the infected and uninfected breasts of the same woman showed no difference in CRP content.

Epidermal Growth Factor. EGF is one of several growth factors found in breast milk, which was first characterized over three decades ago (Schaudies et al. 1990). EGF is a peptide with significant interspecific structural homology (Marti et al. 1989), and milk EGF is both sourced from maternal circulation and synthesized locally in mammary tissue. Concentrations in breast milk range from 30 - to 1,000-fold higher than in circulation, with variations across lactation (Donovan and Odle 1994). EGF is an important regulator of normal gastrointestinal growth and development and also plays an important role in the healing of intestinal injury (e.g., Playford et al. 2000). Significantly higher EGF concentrations in the milk of mothers of extremely preterm infants (compared with mothers of preterm and full-term infants) provide additional evidence of important protective functions (Dvorak et al. 2003).

Transforming Growth Factor- $\boldsymbol{\beta}_{2}$. TGF- $\beta_{2}$ is an anti-inflammatory cytokine with several functions, including modulation of immune responses, inflammation, and allergy and regulation of cell proliferation and differentiation (Rautava et al. 2010; Oddy and McMahon 2011). Experimental studies strongly support the notion that TGF- $\beta$ is necessary for normal immune maturation and, more 
specifically, that breast milk provides the major exogenous source of this cytokine while systemic and mucosal immune systems are developing (Oddy and Rosales 2010; Kainonen et al. 2013). TGF- $\beta_{2}$ is the most prevalent isoform of TGF- $\beta$ in breast milk (Penttila 2010), and in vitro digestion models suggest survival in the infant digestive system (Lönnerdal 2010). Recent studies suggest that maternal history of exposure to microbial pathogens can elevate TGF- $\beta$ concentrations in milk (Peroni et al. 2010). For example, women who emigrated from developing countries to Sweden produced milk with significantly higher levels of TGF- $\beta$ than did women born in Sweden (Amoudruz et al. 2009), suggesting that early-life environments could play a more important role than adult environment in determining the level of TGF- $\beta$ in breast milk.

In sum, we deduce that Aeta (hunter-gatherer) women have been exposed to higher rates of morbidity and mortality than have Ilocano (agricultural) women. As a result of this life environment, we predict that the breast milk of Aeta mothers will have higher concentrations of adiponectin, CRP, EGF, and TGF- $\beta_{2}$ compared with that of Ilocano women. The early-life environment of Aeta mothers born during the early 1990s (1991-1994) was particularly adverse, and we predict that milk from this cohort of women will contain the highest concentrations of adiponectin, CRP, EGF, and TGF- $\beta_{2}$.

\section{Materials and Methods}

Study Sites and Subjects. In March 2011, research was conducted with consenting women in three settlements in Capas municipality, Tarlac Province, Central Luzon, Philippines: Maruglo $(n=25)$, Patalbato $(n=14)$, and Ye Young $(n=16)$ (Figure 2). This region was evacuated during the eruption of Mount Pinatubo, but it suffered relatively less damage from the ensuing lahars and floods (Bautista 1996). Aeta-farmer admixture in Tarlac Province is common (Barrows 1910; Madriaga and Lacanlale 2011), and swidden (kaingin) farming is supplemented with traditional hunting and gathering (Niehof 2010). For each subject, semistructured interviews were conducted to collect information on self-reported ethnic identity (Aeta or Ilocano), maternal and infant ages, and recent illness (during the previous six months).

Sample Collection. Self-expressed milk $(2-5 \mathrm{ml})$ was collected from each breast in plastic tubes 1-3 $\mathrm{h}$ after the morning meal. The samples were then transported in a cooler to a storage facility, where they were vortexed, divided into $500-\mu \mathrm{l}$ aliquots $\left(1.0-\mathrm{ml}\right.$ Eppendorf tubes), and frozen at $-20^{\circ} \mathrm{C}$. The samples were then shipped packaged in dry ice to George Washington University and stored at $-80^{\circ} \mathrm{C}$. Before analysis, the samples were thawed overnight in a refrigerator and vortexed continuously to ensure sample uniformity.

Analytical Methods. We measured adiponectin and EGF levels using the 


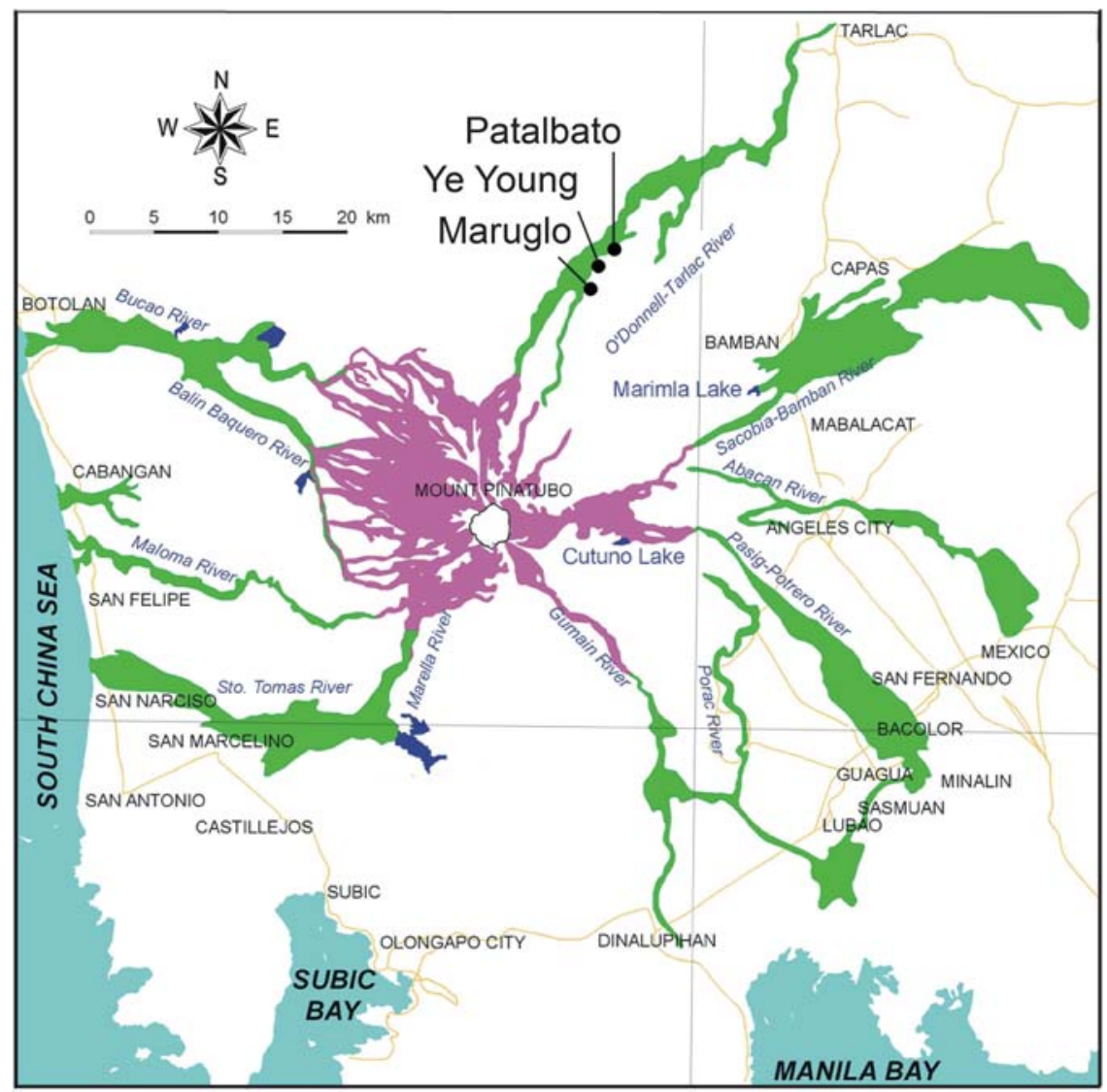

Figure 2. The locations of our three study sites. Colored areas radiating from the caldera represent the cumulative extent of damage from pyroclastic flows (purple) and lahars (green) between 1991 and 1997 (map by Norman Tungol, Philippine Institute of Volcanology and Seismology).

human adiponectin and EGF DuoSet ELISA development kits (R\&D Systems, MN, USA), following the manufacturer's protocols; all samples were diluted 1:5 before adiponectin assay and 1:200 before EGF assay. TGF- $\beta_{2}$ levels were measured using the Quantikine Human TGF- $\beta_{2}$ immunoassay kit (R\&D Systems), following the manufacturer's protocol. We measured milk CRP using the CRP ELISA (hsCRP) kit from ALPCO (NH, USA); samples were diluted 1:3 before CRP assay.

Parallelism and Recovery Protocols. Because these component kits were not developed for use with milk, we performed parallelism and recovery tests to validate that they accurately measured our analytes of interest. Briefly, we pooled several aliquots of milk from different individuals. These pooled samples were 
serially diluted and run in an assay along with the standard curve supplied by the manufacturer. We then tested the parallelism of the slopes of the standard and serially diluted pooled curves. Next, we utilized recovery tests to determine whether compounds in the sample matrix interfered with antibody binding. To do this, we spiked our samples with controls provided in the kit and measured the percent value recovered. For all tests, we centrifuged samples to separate the fat layer and used the aqueous fraction for our assays.

Data Analysis. We performed Welch $t$-tests in R version 2.14.1 (R Development Core Team 2011) to assess whether the levels of each bioactive factor varied as a function of population (Aeta or Ilocano) or birth cohort (pre- and post-1991); all tests were one-tailed, reflecting our a priori hypothesis that Aeta women would express higher concentrations of each bioactive factor. To control for confounding variables such as maternal age, infant age, or recent sickness, we used multiple regression models. In some cases, these variables explained a larger proportion of variation than either birth cohort or population membership, while in others these full models were not significant. All tests were performed with significance levels of $\alpha=0.05$.

\section{Results}

We measured levels of four bioactive factors in the breast milk of 24 Aeta (median age, 23.5 years; range, 16-38 years) and 31 Ilocano (median age, 28.5 years; range, $17-45$ years) mothers. The combined levels in both populations (Table 2) did not vary as a function of maternal age, infant age, or recent sickness (adiponectin: $F_{3,49}$ $=1.44, p=0.24$; CRP: $F_{3,30}=0.10, p=0.96$; EGF: $F_{3,49}=1.1, p=0.37$; TGF- $\beta_{2}$ : $\left.F_{3,49}=0.4, p=0.75\right)$. Accordingly, we used Welch one-sided $t$-tests to compare each compound in both populations. Contrary to our prediction, we found no difference in the levels of adiponectin $(t=-0.4, \mathrm{df}=41, p=0.34), \mathrm{CRP}(t=-0.4$, df $=30.3$, $p=0.34)$, EGF $(t=-0.9, \mathrm{df}=27.9, p=0.19)$, or TGF- $\beta_{2}(t=-1.3$, df $=30, p=$ $0.10)$. The marginal nonsignificance of this latter result was investigated further, as TGF- $\beta_{2}$ also varied as a positive function of maternal age (Figure 3 ).

We found that variation in TGF- $\beta_{2}$ was better explained by Aeta classification $(t=1.8 ; p=0.08)$ than by maternal age $(t=1.5 ; p=0.15)$, although the full model was not significant at the $\alpha=0.05$ level $\left(F_{2,51}=2.02, p=0.14\right)$. This last result reflects the large statistical leverage of a woman who was also pregnant at the time of our study. Although the effects of simultaneous gestation and lactation on the expression of TGF- $\beta_{2}$ are uncertain, the removal this outlier had a large effect on the significance of our model $\left(F_{2,49}=7.90, p=0.001\right)$, suggesting that TGF- $\beta_{2}$ does vary as a positive function of maternal age $(t=3.7 ; p<0.001)$ and Aeta classification $(t=2.6 ; p=0.01)$.

Levels of adiponectin and CRP did not differ between Aeta and Ilocano cohorts born before or after the eruption of Mount Pinatubo (before and after 1991): Aeta (adiponectin: $t=0.5, \mathrm{df}=13.4, p=0.65$; CRP: $t=-0.7, \mathrm{df}=7.3, p=0.53$ ) 
Table 2. Means (Ranges) of Components in Milk of Aeta and Ilocano Women Born before or after the Eruption of Mount Pinatubo

\begin{tabular}{|c|c|c|c|c|c|}
\hline $\begin{array}{l}\text { POPULATION/ } \\
\text { BIRTH COHORT }\end{array}$ & $\begin{array}{l}\text { SAMPLE } \\
\text { SIZE }\end{array}$ & $\begin{array}{l}\text { ADIPONECTIN } \\
\text { (NG/ML) }\end{array}$ & $\begin{array}{c}\text { CRP } \\
(\mathrm{NG} / \mathrm{ML})\end{array}$ & $\begin{array}{c}\mathrm{EGF} \\
(\mathrm{PG} / \mathrm{ML})\end{array}$ & $\begin{array}{c}\text { TGF- }{ }_{2} \\
\text { (PG/ML) }\end{array}$ \\
\hline Aeta & 24 & $\begin{array}{c}4.4 \\
(1.0-11.2)\end{array}$ & $\begin{array}{c}51.5 \\
(5.3-229.0)\end{array}$ & $\begin{array}{c}19,010 \\
(2,897-85,960)\end{array}$ & $\begin{array}{c}4,027 \\
(501-25,620)\end{array}$ \\
\hline Before 1991 & 15 & $\begin{array}{c}4.2 \\
(1.0-8.4)\end{array}$ & $\begin{array}{c}63.9 \\
(5.3-229.0)\end{array}$ & $\begin{array}{c}18,030 \\
(2,897-85,960)\end{array}$ & $\begin{array}{c}3,659 \\
(575-8,295)\end{array}$ \\
\hline After 1991 & 9 & $\begin{array}{c}4.7 \\
(2.5-11.2)\end{array}$ & $\begin{array}{c}39.1 \\
(6.3-99.2)\end{array}$ & $\begin{array}{c}20,640 \\
(11,190-29,500)\end{array}$ & $\begin{array}{c}4,641 \\
(501-25,620)\end{array}$ \\
\hline Ilocano & 31 & $\begin{array}{c}4.2 \\
(2.2-10.2)\end{array}$ & $\begin{array}{c}41.4 \\
(5.3-308.0)\end{array}$ & $\begin{array}{c}15,940 \\
(4,441-30,890)\end{array}$ & $\begin{array}{c}2,550 \\
(692-9,861)\end{array}$ \\
\hline Before 1991 & 28 & $\begin{array}{c}4.2 \\
(2.2-10.2)\end{array}$ & $\begin{array}{c}44.5 \\
(5.3-308.0)\end{array}$ & $\begin{array}{c}15,410 \\
(4,441-30,360)\end{array}$ & $\begin{array}{c}2,723 \\
(692-9,861)\end{array}$ \\
\hline After 1991 & 3 & $\begin{array}{c}4.2 \\
(3.8-4.4)\end{array}$ & $\begin{array}{c}11.99 \\
(5.3-18.7)\end{array}$ & $\begin{array}{c}19,480 \\
(9,811-30,890)\end{array}$ & $\begin{array}{c}1,378 \\
(969-1,644)\end{array}$ \\
\hline
\end{tabular}

Abbreviations: CRP, C-reactive protein; EGF, epidermal growth factor; TGF- $\beta_{2}$, transforming growth factor- $\beta_{2}$.

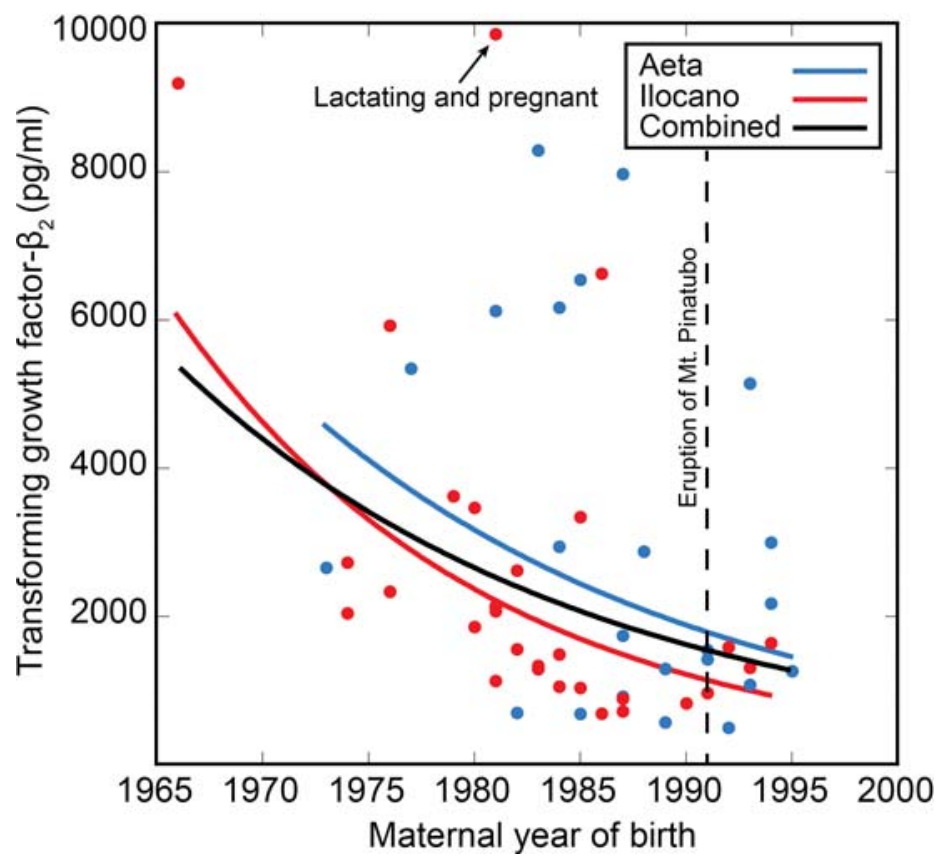

Figure 3. Variation in the anti-inflammatory cytokine TGF- $\beta_{2}$ as a function of maternal age. At all ages, Aeta women tended to produce milk with higher levels of TGF- $\beta_{2}$, although the difference was not significant statistically $(p=0.08)$. The removal an Ilocano outlier, the only mother in our study who was also pregnant, resulted in a significant difference ( $p=$ 0.01 ) between Aeta and Ilocano breast milk composition (see Results for further details). 
and Ilocano (adiponectin: $t=0.08, \mathrm{df}=29, p=0.93$; CRP: $t=-1.7, \mathrm{df}=17.6, p$ $=0.12$ ). In contrast, we detected significantly greater levels of EGF in the milk of Aeta women born after $1991(t=2.7, \mathrm{df}=15.4, p=0.02)$, whereas we found no similar difference between Ilocano cohorts $(t=0.9$, $\mathrm{df}=3.3, p=0.42$; Figure $4 \mathrm{~A})$. This latter result was investigated further because EGF varies as a negative function of infant age (Figure 4B) and because the youngest Aeta women nursed younger infants at the time of our study (Figure 4C). We found that linear models including maternal and infant ages explained a significant amount of the variation in EGF for both post-1991 cohorts (Aeta: $R^{2}=0.3, F_{3,19}=4.1, p=0.02$; Ilocano: $R^{2}$ $\left.=0.29, F_{3,26}=5.0, p=0.007\right)$. Lastly, levels of TGF- $\beta_{2}$ were lower in both post-1991 cohorts (Aeta: $t=-1.8, \mathrm{df}=21, p=0.08$; Ilocano: $t=-2.73$, $\mathrm{df}=29, p=0.01$ ), but this variation is better explained by maternal age $(t=1.7 ; p=0.09)$ than by birth cohort $(t=-1.5, p=0.14)$, although the full model was not significant at the $\alpha=$ 0.05 level $\left(F_{2,51}=1.5 ; p=0.23\right)$.

\section{Discussion}

Our analysis of adiponectin, CRP, EGF, and TGF- $\beta_{2}$ in the milk of Aeta and Ilocano women revealed few detectable differences between populations or between cohorts born before or after the eruption of Mount Pinatubo. Median levels of adiponectin in our study were substantially lower (by a factor of 2-5) than those reported from women in Italy, Mexico, and the United States (Woo et al. 2009; Savino et al. 2012). We also observed variation in EGF as a negative function of infant age (Figure 4B), a result that agrees well with earlier studies (Donovan and Odle 1994). Perhaps importantly, we observed relatively elevated levels of TGF- $\beta_{2}$ in the milk of Aeta women, suggesting a greater exposure to infectious pathogens (Amoudruz et al. 2009; Peroni et al. 2010); however, median levels in Aeta and Ilocano milks (2,419 and $1,644 \mathrm{pg} / \mathrm{ml}$, respectively) were lower than mean values from Mali $(3,727 \mathrm{pg} / \mathrm{ml})$ and Sweden $(3,703 \mathrm{pg} / \mathrm{ml})$ (Holmlund et al. 2010). Such a difference highlights the potential for global variation in the baseline values of some cytokines (McDade et al. 2009).

At least four factors can account for our comparable findings. First, our underlying assumption that Aeta women are more exposed to inflammation and undernourishment might be false. To explore this possibility, it would be advantageous to study inflammatory cytokines in the Ati, a population known to have relatively high morbidity rates (Cadeliña and Cadeliña 1988) and serological evidence of undernutrition (Clavano-Harding et al. 1999). Second, our statistical analysis was underpowered due to a limited sample size. A post hoc power analysis of the between-groups comparison effect sizes (adiponectin, $d=0.11$; CRP, $d=0.14$; EGF, $d=0.26$ ) revealed that $N$ values of $1,189,806$, and 240 individual samples, respectively, would be needed from each population to obtain statistical power at the recommended 0.80 level. Third, intermarriage between the Aeta and Ilocano is prevalent and long-standing in Tarlac Province where our study was conducted (Barrows 1910; Madriaga and Lacanlale 2011). Genetic and cultural admixture 
A

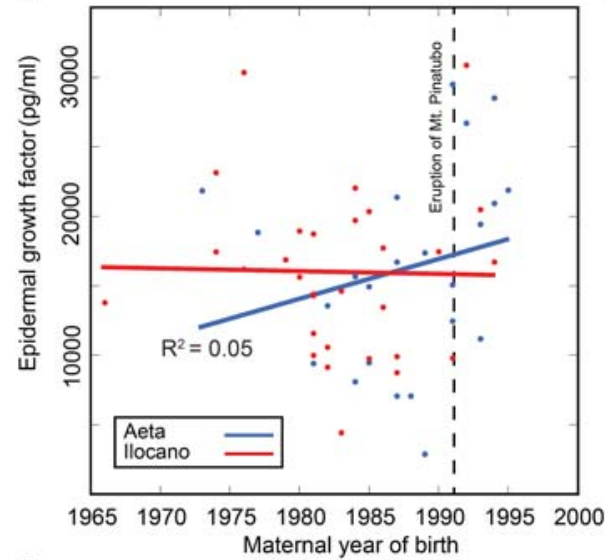

C

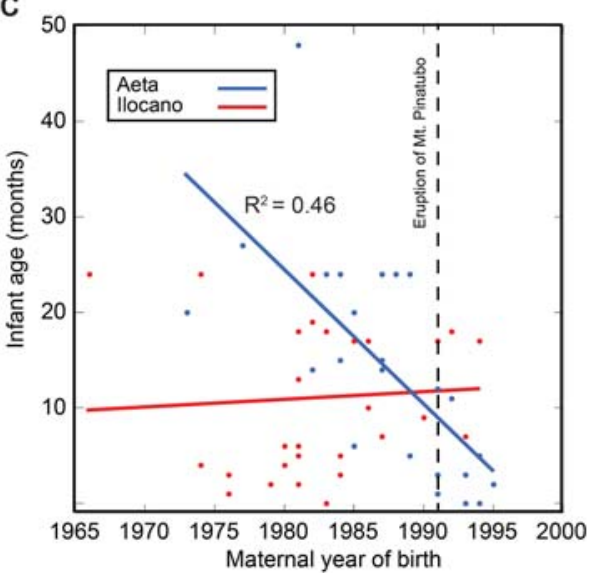

B

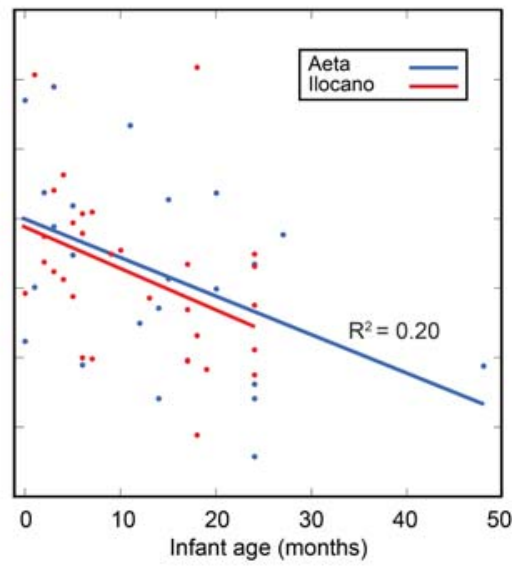

Figure 4. (A and B) Variation in epidermal growth factor (EGF) as a function of maternal age (A) and infant age (B). (C) Relatively elevated levels of EGF in the milk of Aeta woman born after the eruption of Mount Pinatubo in 1991 are caused by young Aeta mothers nursing relatively young infants during our study.

could obscure potential differences in maternal immune responses. Finally, the damage from pyroclastic flows and lahars was relatively minor in Tarlac Province (Bautista 1996; Figure 2). As a result, the northern slopes of Mount Pinatubo still support traditional swidden (kaingin) farming and some hunting and gathering activities (Niehof 2010). If relatively elevated levels of adiponectin, CRP, EGF, and TGF- $\beta_{2}$ exist in the milk of Aeta women born in the early 1990s, they are most likely to be found among women who formerly inhabited the western slopes of Mount Pinatubo. These Aeta-now living in the Baqulian and Loob Bunga settlements near Botolan - were most adversely affected by the eruption (Seitz 2004), and their mortality rates are known to be high (Migliano et al. 2007).

Figure 4C illustrates a potentially important difference in reproductive ecology: in our study, older Aeta mothers were significantly more likely to be nursing older infants, whereas no similar pattern was detected among Ilocano mothers. Such data, if representative, are consistent with reports of unusually long 
interbirth intervals (35 months) among the Aeta (Gawlik et al. 2011), but not with the correlation between higher birth orders and shorter interbirth intervals among the Agta (Goodman et al. 1985). Extended nursing by older Aeta mothers could be a means of suppressing ovulation and regulating population size under unfavorable conditions (Konner and Worthman 1980) or a "terminal investment" in infants born later during the maternal life cycle (Williams 1966; Fessler et al. 2005; Hoffman et al. 2010). For example, the terminal children of Dobe !Kung mothers are typically weaned at 48 months, or as late as 60 months, although the average age of infant weaning is $28-35$ months (Howell 2010). The immunological consequences of this behavior are potentially profound, as terminal infants are predicted to ingest a greater cumulative dosage of TGF- $\beta_{2}$ due to the higher concentrations of this cytokine in the milk of older mothers (Figure 3). Such a pattern could hold for other, as yet untested, milk factors that regulate somatic growth and metabolic programming (e.g., leptin, ghrelin). If so, terminal children, who can survive to represent $30 \%$ of adults in a population (Howell 2010), could be "programmed" to express accelerated life history attributes (small stature, early reproductive maturity) relative to their older siblings. The fitness of later-birth-order individuals could be greater under conditions of high mortality, resulting in a population of short-statured peoples (Migliano et al. 2007).

Although speculative, this discussion highlights the potential importance of the TGF- $\beta$ signaling pathway for regulating immunity, growth, and development (Santibañez et al. 2011; Chang et al. 2002). Perhaps compellingly, genes in this pathway play an important role during osteogenesis, a regulatory pattern that speaks to the functional integration of the TGF- $\beta$ signaling pathway at different life history stages, raising the possibility that environment-gene interactions, or epigenetic factors, can contribute to the pygmy phenotype. Future studies should explore whether genes in the TGF- $\beta$ signaling pathway differentiate between agriculturalists and hunter-gatherers who express the pygmy phenotype. In addition, future studies should include measurements of milk volume, where possible, and nursing activity logs in order to allow interpretation of findings such as those reported here in the context of total yields (e.g., do mothers with higher concentrations of milk EGF produce more or less milk than mothers with lower concentrations, or more important, do infants of mothers with higher or lower milk EGF consume more or less milk?). Such information will be crucial for situating these results within a causative framework.

Although our analysis of four bioactive factors in 55 women represents a negative or inconclusive test of the hypothesis that milk compounds can communicate past infectious environments to the developing infant, we believe that the unique circumstances facing the Aeta offer promise as a model system for testing epigenetic hypotheses focused on the relationships between adult mortality, age of reproductive maturity, and stature. 
Acknowledgments. We are grateful to the women who participated in our study. We also thank C. P. Cabinta, S. M. Sunggod, and the National Commission on Indigenous Peoples for permission to conduct this research. Data collection was approved by the Committee on the Protection of Human Subjects at Dartmouth College (protocol no. 22410). Lastly, we thank G. Benjamin, L. D. Dagsaan, E. J. Dagsaan, H. Drought, K. M. Endicott, P. Endicott, H. Glowacka, T. S. Kraft, A. B. Migliano, C. G. Newhall, E. G. Snow, J. T. Stock, V. V. Venkataraman, and two anonymous reviewers for their practical and technical contributions. Funding was received from the Friedman Family Fellowship (Dartmouth College) and the David and Lucile Packard Foundation (Fellowship in Science and Engineering 2007-31754).

Received 1 October 2012; revision accepted for publication 23 April 2013.

\section{Literature Cited}

Acaba, J. P. 2008. The Aeta's relocation and their struggle for survival. Philipp. Popul. Rev. 7:85-91. Adair, L. S. 2001. Size at birth predicts age at menarche. Pediatrics 107:e59.

Allingham, R. R. 2008. Assessment of visual status of the Aeta, a hunter-gatherer population of the Philippines (an AOS thesis). Trans. Am. Ophthalmol. Soc. 106:240-251.

Amoudruz, P., U. Holmlund, J. Schollin et al. 2009. Maternal country of birth and previous pregnancies are associated with breast milk characteristics. Pediatr. Allergy Immunol. 20:19-29.

Barrows, D. P. 1910. The Negrito and allied types in the Philippines. Am. Anthropol. 12:358-376.

Bautista, C. B. 1996. The Mount Pinatubo disaster and the people of Central Luzon. In Fire and Mud: Eruptions and Lahars of Mount Pinatubo, Philippines, C. G. Newhall and R. S. Punongbayan, eds. Seattle: University of Washington Press, 151-161.

Becker, N. S. A., P. Verdu, A. Froment et al. 2011. Indirect evidence for the genetic determination of short stature in African Pygmies. Am. J. Phys. Anthropol. 145:390-401.

Becker, N. S. A., P. Verdu, B. Hewlett et al. 2010. Can life history trade-offs explain the evolution of short stature in human pygmies? A response to Migliano et al. (2007). Hum. Biol. 82:17-27.

Bernt, K. M., and W. A. Walker. 1999. Human milk as a carrier of biochemical messages. Acta Paediatr. 88:27-41.

Brandtzaeg, P. 2010. The mucosal immune system and its integration with the mammary glands. $J$. Pediatr. 156:S8-S15.

Brosius, J. P. 1990. After Duwagan: Deforestation, Succession, and Adaptation in Upland Luzon, Philippines. Ann Arbor: Center for South and Southeast Asian Studies, University of Michigan.

Cadeliña, R. V., and V. V. Cadeliña. 1988. Morbidity patterns of upland farmers: A comparative study between the Lake Balinsasayao and the Ata population groups. Silliman J. 35:253-265.

Chang, H., C. W. Brown, and M. M. Matzuk. 2002. Genetic analysis of the mammalian transforming growth factor- $\beta$ superfamily. Endocr. Rev. 23:787-823.

Clavano-Harding, A. B., G. R. Ambler, C. T. Cowell et al. 1999. Initial characterization of the GH-IGF axis and nutritional status of the Ati Negritos of the Philippines. Clin. Endocrinol.51:741-747.

D'Alessandro, A., A. Scaloni, and L. Zolla. 2010. Human milk proteins: An interactomics and updated functional overview. J. Proteome Res. 9:3,339-3,373.

Danesh, J., J. G. Wheeler, G. M. Hirschfield et al. 2004. C-reactive protein and other circulating markers of inflammation in the prediction of coronary heart disease. N. Engl.J. Med.350:1,387-1,397.

Dávila, N., B. T. Shea, K. Omoto et al. 2002. Growth hormone binding protein, insulin-like growth factor-I and short stature in two pygmy populations from the Philippines. J. Pediatr. Endocrinol. Metab. 15:269-276. 
del Fierro, V. N. 1918. The Aetas of Zambales. In Ethnography of the Negrito-Aeta Peoples: A Collection of Original Sources, H. O. Beyer, ed. Manila.

Delfin, F., J. M. Salvador, G. C. Calacal et al. 2011. The Y-chromosome landscape of the Philippines: Extensive heterogeneity and varying genetic affinities of Negrito and non-Negrito groups. Eur. J. Hum. Genet. 19:224-230.

De Souza, R. G. 2006. Body size and growth: The significance of chronic malnutrition among Casiguran Agta. Ann. Hum. Biol. 33:604-619.

Donovan, S. M., and J. Odle. 1994. Growth factors in milk as mediators of infant development. Аnnu. Rev. Nutr. 14:147-167.

Dvorak, B., C. C. Fituch, C. S. Williams et al. 2003. Increased epidermal growth factor levels in human milk of mothers with extremely premature infants. Pediatr. Res. 54:15-19.

Early, J. D., and T. N. Headland. 1998. Population Dynamics of a Philippine Rain Forest People: The San Ildefonso Agta. Gainesville: University Press of Florida.

Ellison, P. T., and G. Jasienska. 2007. Constraint, pathology, and adaptation: How can we tell them apart? Am. J. Hum. Biol. 19:622-630.

Fessler, D. M. T., C. D. Navarrete, W. Hopkins et al. 2005. Examining the terminal investment hypothesis in humans and chimpanzees: Associations among maternal age, parity, and birth weight. Am. J. Phys. Anthropol. 127:95-104.

Fetherston, C. M., J. I. Wells, and P. E. Hartmann. 2006. Severity of mastitis symptoms as a predictor of C-reactive protein in milk and blood during lactation. Breastfeed. Med. 1:127-135.

Fox, R. B. 1952. The Pinatubo Negritos: Their useful plants and material culture. Philipp. J. Sci. 81:173-391.

Gaillard, J.-C. 2006. Was it a cultural disaster? Aeta resilience following the 1991 Mt Pinatubo eruption. Philipp. Q. Cult. Soc. 34:376-399.

Gaillard, J.-C. 2007. Resilience of traditional societies in facing natural hazards. Disaster Prev. Mgmt. 16:522-544.

Gaillard, J.-C., and V. Le Masson. 2007. Traditional societies' response to volcanic hazards in the Philippines. Mt. Res. Dev. 27:313-317.

Garvan, J. M., and H. Hochegger. 1964. The Negritos of the Philippines. Horn: Verlag Ferdinand Berger.

Gawlik, A., R. S. Walker, and Z. Hochberg. 2011. Impact of infancy duration on adult size in 22 subsistence-based societies. Acta Paediatr. 100:e248-e252.

Goodman, M. J., A. Estioko-Griffin, P. B. Griffin et al. 1985. Menarche, pregnancy, birth spacing and menopause among the Agta women foragers of Cagayan Province, Luzon, the Philippines. Ann. Hum. Biol. 12:169-177.

Griffin, P. B., and A. Estioko-Griffin. 1985. The Agta of Northeastern Luzon: Recent Studies. Cebu City, Philippines: University of San Carlos.

Guernier, V., M. E. Hochberg, and J.-F. Guégan. 2004. Ecology drives the worldwide distribution of human diseases. PLoS Biol. 2:e141.

Gurven, M., H. Kaplan, J. Winking et al. 2008. Aging and inflammation in two epidemiological worlds. J. Gerontol. A Biol. Sci. Med. Sci. 63:196-199.

Headland, T. N., and H. W. Greene. 2011. Hunter-gatherers and other primates as prey, predators, and competitors of snakes. Proc. Natl. Acad. Sci. USA 108:E1,470-1,474.

Hill, K., and A. M. Hurtado. 1996. Ache Life History: The Ecology and Demography of a Foraging People. Hawthorne, NY: Aldine de Gruyter.

Hill, K., A. M. Hurtado, and R. S. Walker. 2007. High adult mortality among Hiwi hunter-gatherers: Implications for human evolution. J. Hum. Evol. 52:443-454.

Hoffman, C. L., J. P. Higham, A. Mas-Rivera et al. 2010. Terminal investment and senescence in rhesus macaques (Macaca mulatta) on Cayo Santiago. Behav. Ecol. 21:972-978.

Holmlund, U., P. Amoudruz, M. A. Johansson et al. 2010. Maternal country of origin, breast milk characteristics and potential influences on immunity in offspring. Clin. Exp. Immunol. 162:500-509. 
Howell, N. 2010. Life Histories of the Dobe!Kung: Food, Fatness, and Well-being over the Life Span. Berkeley: University of California Press.

HUGO Pan-Asian SNP Consortium. 2009. Mapping human genetic diversity in Asia. Science 326:1,541-1,545.

Imrie, H., J. F. Fowkes, P. Michon et al. 2007. Low prevalence of an acute phase response in asymptomatic children from a malaria-endemic area of Papua New Guinea. Am. J. Trop. Med. Hyg. 76:280-284.

Jarvis, J. P., L. B. Scheinfeldt, S. Soi et al. 2012. Patterns of ancestry, signatures of natural selection, and genetic association with stature in western African Pygmies. PLoS Genet. 8:e1002641.

Kainonen, E., S. Rautava, and E. Isolauri. 2013. Immunological programming by breast milk creates an anti-inflammatory cytokine milieu in breast-fed infants compared to formula-fed infants. Br. J. Nutr. 109:1962-1970.

Katzmarzyk, P. T., and W. R. Leonard. 1998. Climatic influences on human body size and proportions: Ecological adaptations and secular trends. Am. J. Phys. Anthropol. 106:483-503.

Kirchengast, S. 2000. Differential reproductive success and body size in !Kung San people from northern Namibia. Coll. Antropol. 24:121-132.

Konner, M., and C. Worthman. 1980. Nursing frequency, gonadal function, and birth spacing among !Kung hunter-gatherers. Science 207:788-791.

Kuzawa, C. W. 2005. Fetal origins of developmental plasticity: Are fetal cues reliable predictors of future nutritional environments? Am. J. Hum. Biol. 17:5-21.

Kuzawa, C. W., and E. A. Quinn. 2009. Developmental origins of adult function and health: Evolutionary hypotheses. Annu. Rev. Anthropol. 38:131-147.

Kuzawa, C. W., P. S. Tallman, L. S. Adair et al. 2012. Inflammatory profiles in the non-pregnant state predict offspring birth weight at Cebu: Evidence for inter-generational effects of low grade inflammation. Ann. Hum. Biol. 39:267-274.

Kuzawa, C. W., and Z. M. Thayer. 2011. Timescales of human adaptation: The role of epigenetic processes. Epigenomics 3:221-234.

Lachance, J., B. Vernot, C. C. Elbers et al. 2012. Evolutionary history and adaptation from highcoverage whole-genome sequences of diverse African hunter-gatherers. Cell 150:457-469.

Lönnerdal, B. 2010. Bioactive proteins in human milk: Mechanisms of action. J.Pediatr. 156:S26-S30.

Madriaga, G. T., and E. P. Lacanlale. 2011. Life pattern of intermarried Aetas and lowlanders in Barangay Sta. Juliana, Capas, Tarlac. Int. Proc. Econ. Dev. Res. 5:290-295.

Marler, T. E. 2011. The Aeta-Pinatubo loop. Commun. Integr. Biol. 4:788-790.

Marti, U., S. J. Burwen, and A. L. Jones. 1989. Biological effects of epidermal growth with emphasis on the gastrointestinal tract and liver: An update. Hepatology 9:126-138.

McDade, T. W. 2003. Life history theory and the immune system: Steps toward a human ecological immunology. Am. J. Phys. Anthropol. 122:100-125.

McDade, T. W. 2005. The ecologies of human immune function. Annu. Rev. Anthropol. 34:495-521.

McDade, T. W., J. N. Rutherford, L. Adair et al. 2008. Adiposity and pathogen exposure predict Creactive protein in Filipino women. J. Nutr. 138:2,442-2,447.

McDade, T. W., J. N. Rutherford, L. Adair et al. 2009. Population differences in associations between C-reactive protein concentration and adiposity: Comparison of young adults in the Philippines and the United States. Am. J. Clin. Nutr. 89:1,237-1,245.

McDade, T. W., J. Rutherford, L. Adair et al. 2010. Early origins of inflammation: Microbial exposures in infancy predict lower levels of C-reactive protein in adulthood. Proc. R. Soc. Lond. B 277:1,129-1,137.

McDade, T. W., P. S. Tallman, L. S. Adair et al. 2011. Comparative insights into the regulation of inflammation: Levels and predictors of interleukin 6 and interleukin 10 in young adults in the Philippines. Am. J. Phys. Anthropol. 146:373-384.

McDade, T. W., and C. M. Worthman. 1999. The weanling's dilemma reconsidered: A biocultural analysis of breastfeeding ecology. J. Dev. Behav. Pediatr. 19:286-299. 
Migliano, A. B. 2005. Why Are Pygmies Small? Ontogenetic Implications of Life History Evolution. Ph.D. diss. Cambridge: University of Cambridge.

Migliano, A. B., I. G. Romero, M. Mespalu et al. 2013. Evolution of the pygmy phenotype: Evidence of positive selection from genome-wide scans in African, Asian, and Melanesian pygmies. Hum. Biol. 85:251-284.

Migliano, A. B., L. Vinicius, and M. M. Lahr. 2007. Life history trade-offs explain the evolution of human pygmies. Proc. Natl. Acad. Sci. USA 104:20,216-20,219.

Migliano, A. B., L. Vinicius, and M. M. Lahr. 2010. Why are pygmies so short? A defense of Migliano's hypothesis. Hum. Biol. 82:109-113.

Moore, S. E., A. C. Collinson, P. Tamba N'Gom et al. 2006. Early immunological development and mortality from infectious disease in later life. Proc. Nutr. Soc. 65:311-318.

Nettleton, J. A., M. B. Schulze, R. Jiang et al. 2008. A priori-defined dietary patterns and markers of cardiovascular disease risk in the Multi-Ethnic Study of Atherosclerosis (MESA). Am. J. Clin. Nutr. 88:185-194.

Newburg, D. S., J. G. Woo, and A. L. Morrow. 2010. Characteristics and potential functions of human milk adiponectin. J. Pediatr. 156:S41-S46.

Newhall, C. G., A. S. Daag, F. G. Delfin et al. 1996. Eruptive history of Mount Pinatubo. In Fire and Mud: Eruptions and Lahars of Mount Pinatubo, Philippines, C. G. Newhall and R. S. Punongbayan, eds. Seattle: University of Washington Press, 165-195.

Newton, P. 1920. Observations on the Negritos of the Philippine Islands. Am. J. Phys. Anthropol. $3: 1-24$.

Niehof, A. 2010. Food, Diversity, Vulnerability and Social Change: Research Findings from Insular Southeast Asia. Wageningen, the Netherlands: Wageningen Academic.

Oddy, W. H., and R. J. McMahon. 2011. Milk-derived or recombinant transforming growth factor-beta has effects on immunological outcomes: A review of evidence from animal experimental studies. Clin. Exp. Allergy 41:783-793.

Oddy, W. H., and F. Rosales. 2010. A systematic review of the importance of milk TGF- $\beta$ on immunological outcomes in the infant and young child. Pediatr. Allergy Immunol. 21:47-59.

Ohenjo, N., R. Willis, D. Jackson et al. 2006. Health of indigenous people in Africa. Lancet. $367: 1,937-1,946$.

Omoto, K. 1989. Genetic studies of human populations in Asian-Pacific area with special reference to the origins of the Negritos. In Current Aspects of Biogeography in West Pacific and East Asian Regions, H. Ohba, I. Hayami, and K. Mochizuki, eds. Tokyo: University Museum, University of Tokyo, 135-146.

Omoto, K., S. Misawa, S. Harada et al. 1978. Population genetic studies of the Philippine Negritos. I. A pilot survey of red cell enzyme and serum protein groups. Am. J. Hum. Genet. 30:190-201.

Oshima, K., A. Nampei, M. Matsuda et al. 2005. Adiponectin increases bone mass by suppressing osteoclast and activating osteoblast. Biochem. Biophys. Res. Commun. 331:520-526.

Penttila, I. A. 2010. Milk-derived transforming growth factor- $\beta$ and the infant immune response. $J$. Pediatr. 156:S21-S25.

Peroni, D. G., L. Pescollderungg, G. L. Piacentini et al. 2010. Immune regulatory cytokines in the milk of lactating women from farming and urban environments. Pediatr. Allergy Immunol. 21:977-982.

Perry, G. H., and N. J. Dominy. 2009. Evolution of the human pygmy phenotype. Trends Ecol. Evol. 24:218-225.

Peterson, J. T. 1978. The Ecology of Social Boundaries: Agta Foragers of the Philippines. Urbana: University of Illinois Press.

Petherick, A. 2010. Mother's milk: A rich opportunity. Nature 468:S5-S7.

Playford, R. J., C. E. Macdonald, and W. S. Johnson. 2000. Colostrum and milk-derived peptide growth factors for the treatment of gastrointestinal disorders. Am. J. Clin. Nutr. 72:5-14.

Rai, N. K. 1990. Living in a Lean-to: Philippine Negrito Foragers in Transition. Ann Arbor: Museum of Anthropology, University of Michigan. 
Rautava, S., N. N. Nanthakumar, A. Dubert-Ferrandon et al. 2010. Breast milk-transforming growth factor- $\beta(2)$ specifically attenuates IL-IB-induced inflammatory responses in the immature human intestine via an SMAD6- and ERK-dependent mechanism. Neonatology 99:192-201.

Rautava, S., and W. A. Walker. 2009. Breastfeeding-An extrauterine link between mother and child. Breastfeed. Med. 4:3-10.

R Development Core Team. 2011. R: A Language and Environment for Statistical Computing. Vienna, Austria: R Foundation for Statistical Computing.

Reed, W. A. 1904. Negritos of Zambales. Manila: Bureau of Public Printing.

Rodolfo, K. S., and J. V. Umbal. 2008. A prehistoric lahar-dammed lake and eruption of Mount Pinatubo described in a Philippine aborigine legend. J. Volcanol. Geoth. Res. 176:432-437.

Rusznak, D. V. 2010. Acculturation and dietary change among the Pinatubo Aetas. J. Grad. Sch. AsiaPacific Stud. 19:171-187.

Santibañez, J. F., M. Quintanilla, and C. Bernabeu. 2011. TGF- $\beta /$ TGF- $\beta$ receptor system and its role in physiological and pathological conditions. Clin. Sci. 121:233-251.

Savino, F., S. A. Liguori, and M. M. Lupica. 2010a. Adipokines in breast milk and preterm infants. Early Hum. Dev. 86:77-80.

Savino F., S. A. Liguori, E. Petrucci et al. 2010b. Evaluation of leptin in breast milk, lactating mothers, and their infants. Eur. J. Clin. Nutr. 64: 972-977.

Savino, F., M. M. Lupica, S. Benetti et al. 2012. Adiponectin in breast milk: Relation to serum adiponectin concentration in lactating mothers and their infants. Acta Paediatr. 101:1,058-1,062.

Savino, F., E. Petrucci, and G. E. Nanni. 2008. Adiponectin: An intriguing hormone for paediatricians. Acta Paediatr. 97:701-705.

Sawada, T. 1992. A report from Tent City-experience in medical relief. In After the Eruption: Pinatubo Aetas at the Crisis of Their Survival, H. Shimizu, ed. Tokyo: Foundation for Human Rights in Asia, 63-73.

Schaudies, R. P., J. Grimes, H. L. Wray et al. 1990. Identification and partial characterization of multiple forms of biologically active EGF in rat milk. Am. J. Physiol. 259:G1056-G1061.

Schebesta, P. 1952. Die Negrito Asiens. I. Band: Geschichte, geographie, umwelt, demographie und anthropologie der negrito. Wien-Mödling: St. Gabriel.

Seitz, S. 1998. Coping strategies in an ethnic minority group: The Aeta of Mount Pinatubo. Disasters 22:76-90.

Seitz, S. 2004. The Aeta at the Mt. Pinatubo, Philippines: A Minority Group Coping with Disaster. Quezon City: New Day.

Seitz, S. 2008. Decision-making in times of disaster: The acceptance of wet-rice cultivation among the Aeta of Zambales, Philippines. In Culture and the Changing Environment. Uncertainty, Cognition, and Risk Management in Cross-cultural Perspective, M. J. Casimir, ed. Oxford: Berghahn, 125-145.

Shimizu, H. 1989. Pinatubo Aytas: Continuity and Change. Quezon City: Ateneo de Manila University Press.

Shimizu, H., ed. 1992. After the Eruption: Pinatubo Aetas at the Crisis of Their Survival. Tokyo: Foundation for Human Rights in Asia.

Stock, J. T., and A. B. Migliano. 2009. Stature, mortality, and life history among indigenous populations of the Andaman Islands, 1871-1986. Curr. Anthropol. 50:713-725.

Tallman, P. S., C. Kuzawa, L. Adair et al. 2012. Microbial exposures in infancy predict levels of the immunoregulatory cytokine interleukin-4 in Filipino young adults. Am. J. Hum. Biol. 24:446-453.

Thayer, Z. M., A. B. Feranil, and C. W. Kuzawa. 2012. Maternal cortisol disproportionately impacts fetal growth in male offspring: Evidence from the Philippines. Am. J. Hum. Biol. 24:1-4.

Thayer, Z. M., and C. W. Kuzawa. 2011. Biological memories of past environments: Epigenetic pathways to health disparities. Epigenetics 6:798-803.

Umbal, J. V. 1997. Five years of lahars at Pinatubo volcano: Declining but still potentially lethal hazards. J. Geol. Soc. Philipp. 52:1-19. 
Walker, R., M. Gurven, K. Hill et al. 2006. Growth rates and life histories in twenty-two small-scale societies. Am. J. Hum. Biol. 18:295-311.

Walker, R. S., and M. J. Hamilton. 2008. Life-history consequences of density dependence and the evolution of human body size. Curr. Anthropol. 49:115-122.

Weyermann, M., C. Beermann, H. Brenner et al. 2006. Adiponectin and leptin in maternal serum, cord blood and breast milk. Clin. Chem. 52:209-212.

Williams, G. C. 1966. Adaptation and Natural Selection. Princeton, NJ: Princeton University Press.

Woo, J. G., M. L. Guerrero, M. Altaye et al. 2009. Human milk adiponectin is associated with infant growth in two independent cohorts. Breastfeed. Med. 4:101-109.

Woo, J. G., M. L. Guerrero, F. Guo et al. 2012. Human milk adiponectin impacts infant weight trajectory during the second year of life. J. Pediatr. Gastroenterol. Nutr. 54:532-539.

Wulster-Radcliffe, M. C., K. M. Ajuwon, J. Wang et al. 2004. Adiponectin differentially regulates cytokines in porcine macrophages. Biochem. Biophys. Res. Commun. 316:924-929.

Zhou, Y., X. Sun, L. Jin et al. 2005. Expression profiles of adiponectin receptors in mouse embryos. Gene Expr. Patterns 5:711-715. 